\title{
Analysis to Bulk Density in Trial Dredged-Trough for Immersed Tube Tunnel
}

\author{
Jie $\mathrm{He}^{1,2, \mathrm{a}}$, Wenjie Xin ${ }^{1,2, \mathrm{c}}$ \\ ${ }^{1}$ Nanjing Hydraulic Research Institute, Nanjing, China \\ ${ }^{2}$ State Key Laboratory of Hydrology-Water Resource and Hydraulic Engineering, Nanjing, China \\ ${ }^{3}$ Hydrology Bureau of Yellow River Conservancy Commission, Zhengzhou, China \\ ajhe_nhri@126.cn, ${ }^{b}$ wjxin2008@126.com
}

Keywords: Trial Dredged-Trough, Sediment Observation, Slope, Fluid Mud.

Abstract. On the basis of studying water-sediment movement in the Lingdingyang sea area, sedimentation characteristics of the trial dredged-trough of immersed tube tunnel of HZMB are analyzed, with 17 groups of underwater topographic survey data and the measured results of fluid mud and silt unit weight in the base trough and slopes. And some results are obtained, including siltation rate changes and its distribution characteristics of the trial dredged-trough, the slope ratio of steady slope, the thickness and its trends of the fluid mud layer and silt layer in the trough. This paper analyzes the statistics of ultrasonic depth-sounding with three different frequencies, and it's found that there is a difference of $0.3 \mathrm{~m}$ between multi-beam and low frequency, which coincides with the measured values of the fluid mud thickness of $0.29 \mathrm{~m}$ very well.

\section{Introduction}

A planned Hong Kong-Zhuhai-Macao Bridge (HZMB), from west Zhuhai Macao to east Hong Kong, crosses the Lingdingyang baymouth of the Pearl River estuary which is the most important waterway along it many large vessels must pass through from Guangzhou, Shenzhen harbors in the South China. In order to meet navigation requirements, a design scheme of a bridge in combination with tunnel has been worked out, i.e. the seabed tunnel structure is placed on the Lingdingyang main navigable section by use of the immersed tube tunnel construction. Because Dahao waterway through which the tunnel passes has a deep waterway with high velocity, a base trough $5400 \mathrm{~m}$ in length and $42 \mathrm{~m}$ in depth must be excavated if the immersed tube tunnel is used. However, a few issues such as excavation of the base trough, sedimentation after excavation, density distribution and slope stability have aroused considerable attention.

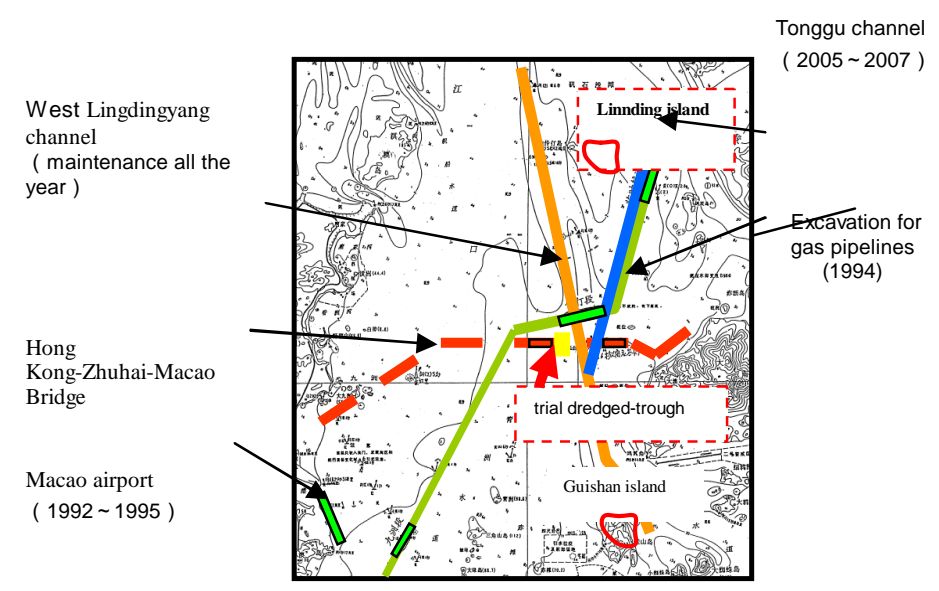

Figure 1 Sketch Of The Trial Dredged-trough

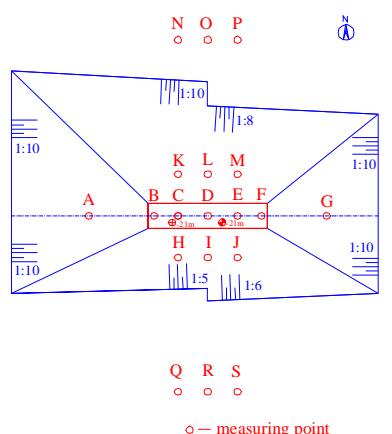

Figure 2 Layout Of the Trial Dreged-Trough and the Observation Points

In order to understand these questions, a sedimentation observation of the trial dredged-trough and its analysis should be carried out in the study. The trial dredged-trough is choosen in the east sea-bed of the west artificial Island, which has a length of $100 \mathrm{~m}$ and $-21 \mathrm{~m}$ in bottom elevation (average depth of 
excavation $11.5 \mathrm{~m}$ ), from east to west, and respectively having the slope ratio of 1:5,1:6 (south side) and 1:8,1:10 (north side). And its location is shown in fig. 1 and its excavation scale is shown in fig. 2. Construction excavation and topographic survey after excavation have been completed by Guangzhou Navigation Bureau Corp. Ltd, and Nanjing Hydraulic Research Institute carried on researches such as sediment bulk density observation and sedimentation analysis.

\section{Field Observation of the Trial of the Dredged-Trough}

\section{Observation Time Period}

The trial dredged-trough was completed on February 6, 2009, and observation period starts from that date until October 14, lasted a total of 250 days, which spans more than eight months, i.e. spring, summer and autumn, during which suffered from a relatively large flood and two typhoons.

Observation Records

(1) Underwater topography survey for slope and the base trough of the trial dredged-trough was done for 17 times using the multi-beam and dual-frequency sounder.

(2) Fluid mud and sludge bulk density detection for slope and the base trough of the trial dredged-trough was done for 4 times using $\gamma$-ray sludge densitometer.

(3) Sea-bed material sampling and particle analysis were done for many times on the seabed excavated as the base trough of the trial dredged-trough and its slope.

The field observation and periods corresponding to items above are listed in table 1.

Tab.1 The Field Observation Items Of The Trial Dredged-trough and Corresponding Statistical Times

\begin{tabular}{|c|c|c|c|c|c|}
\hline No & $\begin{array}{l}\text { Observation } \\
\text { Time }\end{array}$ & Regime & $\begin{array}{c}\text { Topographic } \\
\text { Survey }\end{array}$ & $\begin{array}{l}\text { Bulk Density } \\
\text { Observation }\end{array}$ & $\begin{array}{l}\text { Bed Material } \\
\text { Sampling }\end{array}$ \\
\hline 1 & 2009.02 .06 & \multirow{9}{*}{$\begin{array}{l}\text { Before } \\
\text { flood }\end{array}$} & $\sqrt{ }$ & $\sqrt{ }$ & $\sqrt{ }$ \\
\hline 2 & 2009.02 .15 & & $\sqrt{ }$ & & \\
\hline 3 & 2009.02 .23 & & $\sqrt{ }$ & & \\
\hline 4 & 2009.03 .02 & & $\sqrt{ }$ & & \\
\hline 5 & 2009.03 .10 & & $\sqrt{ }$ & & \\
\hline 6 & 2009.03 .26 & & $\sqrt{ }$ & & \\
\hline 7 & 2009.03 .31 & & $\sqrt{ }$ & & \\
\hline 8 & 2009.04 .11 & & $\sqrt{ }$ & $\sqrt{ }$ & $\sqrt{ }$ \\
\hline 9 & 2009.05 .08 & & $\sqrt{ }$ & & \\
\hline 10 & 2009.05 .27 & \multirow{6}{*}{$\begin{array}{l}\text { During } \\
\text { flood }\end{array}$} & $\sqrt{ }$ & & \\
\hline 11 & 2009.06 .13 & & $\sqrt{ }$ & & \\
\hline 12 & 2009.07.09 & & $\sqrt{ }$ & $\sqrt{ }$ & $\sqrt{ }$ \\
\hline 13 & 2009.07 .24 & & $\sqrt{ }$ & & \\
\hline 14 & 2009.08 .08 & & $\sqrt{ }$ & & \\
\hline 15 & 2009.09 .09 & & $\sqrt{ }$ & & \\
\hline 16 & 2009.09 .24 & \multirow{2}{*}{$\begin{array}{l}\text { After } \\
\text { flood }\end{array}$} & $\sqrt{ }$ & & \\
\hline 17 & 2009.10 .13 & & $\sqrt{ }$ & $\sqrt{ }$ & $\sqrt{ }$ \\
\hline
\end{tabular}

\section{Change in bulk density in the trough}

From field observations of bulk density of deposition it was found that there is fluid mud with silt layer in the trial dredged-trough, and of which the mean thickness of fluid mud is $0.29 \mathrm{~m}$; the mean thickness of soft silt mud is $0.98 \mathrm{~m}$, and their total mean thickness is $1.27 \mathrm{~m}$.

Comparing the total thickness of fluid mud with silt layer for each measuring time, it is shown that the total mean thickness is within $0.2 \mathrm{~m}$ during the trough initially forming, and it has increased to $0.5 \mathrm{~m}$ 2 months after the dry season, and the total mean thickness is up to $0.9 \mathrm{~m}$ after 3 months of the flood season, and the total mean thickness is close to $1.3 \mathrm{~m}$ after 3 months from flood season to the dry. Field 
observation shown that the growth rate of the fluid mud and silt thickness in the trial dredged-trough is not very fast .

From changes in the fluid mud and silt thickness for eight times it is seen that there is not great changes in thickness of the fluid mud and soft silt thickness is remarkably increasing with time. It is shown a phenomenon or process, i.e. the fluid mud in the trough is gradually becoming dense and finally converted into the soft silt. Fig.3 shown the bulk density distribution curves of silt layers obtained from observation of $\mathrm{B}$ and $\mathrm{C}$ points in the trial dredged-trough.

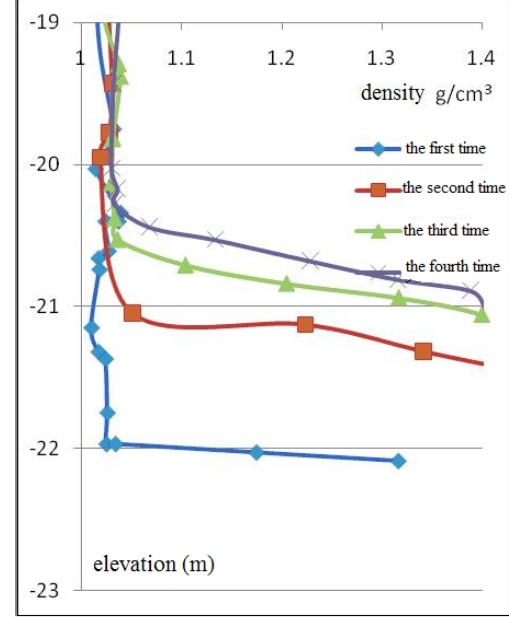

B Point

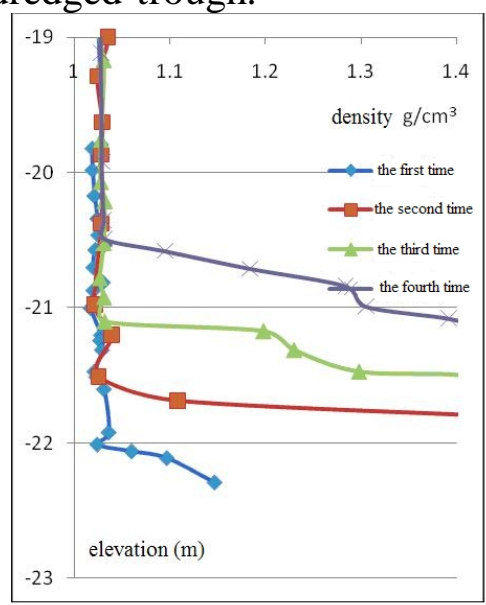

C Point

Fig.3 The Mud Density Distribution Curves With The Depth In The Trial Dredged-trough

\section{Comparisons of measured depth data with different frequencies}

The statistical analysis of changes in topograph in the trial dredged-trough has been maken by use of water depth data obtained from the multi-beam measurements. In order to understanding some differences between the data obtained from the dual-frequency sounder, according to the longitudinal and horizontal sections, the water-depth data with three different frequencies have been respectively recorded from the seventh measured depth data, as listed in table 2. From comparation of data in the table it can be found that all measured depth data average from multi-beam is the minimum, and that from high-frequency is the middle and that from low-frequency is the maximum, and its differences are $0.18 \mathrm{~m}, 0.17 \mathrm{~m}$ (horizontal profile) and $0.14 \mathrm{~m}, 0.13 \mathrm{~m}$ (longitudinal profile) whether the horizontal or longitudinal profiles. However, in the tables it is also found that the depth data of few measuring points from multi-beam is greater than that from the high-frequency (blue data in the table), and data from the low frequency at very few measuring points is the minimum (red data in the table) and that from the high-frequency is the maximum (green data in the table). Most of the measured depth data conformed with distribution regularity, i.e. "the minimum form the multi-beam, the middle from the high-frequency and the maximum form the low-frequency".

The corresponding relations of the measured depth data given by three kinds of frequencies are basically reasonable. It can be found from preliminary estimates that the depth from multi-beam measurement should be $0.15 \mathrm{~m}$ smaller than that from the high-frequency measurement, and the depth from high-frequency measurement is also $0.15 \mathrm{~m}$ smaller than the low-frequency measurement, and there may be $0.30 \mathrm{~m}$ of the thickness deviation between data from the multi-beam and the low-frequency measurements, which conformed with the observed results of the fluid mud thickness very well.

As the multi-beam observed data is very intensive, it is favourable for improving the statistical accuracy, but to some differences should be payed more attention when the data is used because the absolute values of the depth displays small tendencies. 
From comparative analysis it is seen that differences between underwater ultrasonic echo signal interference and impacts should be very great in sometimes under different sediment conditions, thus in most cases, the thickness of fluid mud and silting mud can not be divided only by use of the differences between the high or low frequency measured depth data. $\gamma$-ray density measurement method described in the paper can be used in calibration of the dual-frequency sounder.

Tab.2 Depth Data Comparisons Of The 7th Measuring Time With Different Frequencies Of The Horizontal Profile

\begin{tabular}{|c|c|c|c|}
\hline \multirow{2}{*}{$\begin{array}{l}\text { Distance Form West } \\
\text { Starting Point }(\mathrm{m})\end{array}$} & \multicolumn{3}{|c|}{ Depth $(\mathrm{m})$} \\
\hline 0 & Multi-beam & High-frequency & Low-frequency \\
\hline 10 & 11.70 & 11.90 & 12.10 \\
\hline 20 & 12.25 & 12.90 & 13.10 \\
\hline 30 & 13.65 & 13.74 & 13.90 \\
\hline 40 & 15.43 & 15.90 & 16.10 \\
\hline 50 & 17.20 & 17.50 & 17.60 \\
\hline 60 & 18.20 & 19.10 & 19.40 \\
\hline 70 & 20.20 & 20.60 & 20.80 \\
\hline 80 & 21.20 & 21.52 & 21.62 \\
\hline 90 & 21.33 & 21.20 & 21.50 \\
\hline 100 & 20.30 & 20.30 & 20.40 \\
\hline 110 & 19.20 & 18.90 & 19.30 \\
\hline 120 & 17.80 & 17.80 & 17.80 \\
\hline 130 & 16.60 & 16.90 & 17.00 \\
\hline 140 & 16.00 & 16.00 & 14.10 \\
\hline 150 & 14.80 & 14.80 & 14.10 \\
\hline Average & 14.00 & 14.10 & 17.39 \\
\hline & 17.04 & 17.22 & \\
\hline
\end{tabular}

\section{Conclusions}

From comparative analysis of the depth data given by three measurement methods(high, low-frequency and multi-beam) it is seen that there is a corresponding relationship among the three methods, i.e. the depth from multi-beam measurement is $0.15 \mathrm{~m}$ smaller than that from the high-frequency measurement, and the depth from high-frequency measurement is also $0.15 \mathrm{~m}$ smaller than the low-frequency measurement, and there is $0.30 \mathrm{~m}$ of the thickness difference between data from the multi-beam and the low-frequency measurements, which conformed with the observed results of $0.29 \mathrm{~m}$ in thickness of the fluid mud very well.

\section{References}

[1] Xu Jun-liang et al.(1993) .Evolution and Development of the Pearl River Delta Waterways with Ports and Rational Harbor Layout . China Ocean Press, 1993(3),pp12-18.

[2] Chen Yao-tai et al. (1992).Modern sedimentary velocity and sedimentary environment in the Pearl River mouth.Journal of Zhongshan University (Natural Science), Volume Two,Issue 31.

[3] Li Chun-chu, Lei Ya-ping, He Wei et al. (2002).Evolutional processes of the Pearl River estuary and its protective regulation and exploitation.Journal of Sediment Research, pp44-51

[4] Chen Zhi-min, Cai Nan-shu, Xin Wen-jie.(2002).Analysis on the sedimentation of the Lingdingyang channel in the Zhujiang estuary. The Ocean Engineering, Volume Twenty, Issue 3. 